\title{
Readiness in Evaluation: Three Prompts for Evaluators
}

\section{Ricardo Ramírez, Dal Brodhead, and Wendy Quarry}

DECl-2

\begin{abstract}
The notion of readiness in evaluation is often tacit: it can be hidden in the Request for Proposals by a granting agency calling for an evaluation; or, at best, it is hinted at in the winning consultant's bid. We are practitioners committed to learning-oriented, practical evaluations. However, we have found that the extent to which the client is ready for a collaborative, utilization-focused evaluation (UFE) that enhances organizational learning is often taken for granted. We have learned to address "readiness" early on, as it is a lynchpin that shapes every subsequent step of the process. We bring attention to the examples from our practice to highlight three dimensions of readiness: the power to design, the commitment to learn, and building an evaluation culture.
\end{abstract}

Keywords: collaborative evaluation, decision making, organizational learning, readiness, utilization-focused evaluation

Résumé : Le fait d'être prêt pour l'évaluation est souvent traité de façon implicite: Cette notion est souvent occultée dans les appels de propositions des organismes subventionnaires pour des projets évaluatifs; dans le meilleur des cas, la proposition gagnante y fait allusion. En tant que praticiens de l'évaluation, nous nous engageons à favoriser l'apprentissage et à offrir des évaluations pragmatiques. Nous avons toutefois constaté qu'il est souvent pris pour acquis que le client est prêt pour une évaluation collaborative, axée sur l'utilisation, qui améliore l'apprentissage organisationnel. Notre expérience démontre l'importance d'apprécier si c'est effectivement le cas puisque c'est une composante qui influencera chaque étape subséquente du processus évaluatif. Nous apportons ici des exemples tirés de notre pratique pour mettre en évidence trois dimensions centrales au fait d'être prêt pour l'évaluation : le pouvoir de création, l'engagement à apprendre et la construction d'une culture évaluative.

Mots clés : évaluation collaborative, prise de décision, apprentissage organisationnel, évaluation axée sur l'utilisation

Correspondance à l'auteur: Ricardo Ramirez, co-principal investigator, DECI, 33 Caledonia Street, Guelph, ON, N1G 2C9; ramirez2196@sympatico.ca 


\section{THE STORY}

We were a team of five meeting in Cape Town. While all had evaluation experience, each brought different worldviews to the task and only two had worked through a utilization-focused approach to evaluation in the past. We had all met briefly once before and had had barely a glimpse of the executive director of the organization we would be evaluating. Apart from these brief encounters, we were new to each other as an evaluation team, largely new to utilization-focused evaluation, and definitely new to this regional organization.

The organization's offices are on the second floor of the renovated Old Castle Brewery in Woodstock, just east of the Cape Town city centre. Everything about the building and about the office was a reminder that what this team was working on was about shaping policy for the future. The organization itself was positioned to make broadband telecommunication as accessible as possible to a larger population across Africa. We climbed the iron staircase to a crow's nest boardroom perched on the edge of a loft with a full view of the city and a glimpse of Table Mountain.

How could we work in this heady atmosphere? Well, we could, and we certainly did. The whole premise of our collaborative approach to evaluation is to work with, rather than for, the organization being evaluated. It was important to make it clear that the organization under review would "own" this evaluation, so staff members would have to roll up their sleeves and decide for themselves who would be the main "users" of the evaluation, what would be its intended "uses," and how the key evaluation questions would be framed to make sure the data collected responded to their own intended uses-their interests and needs. These interests were expected to be somewhat like those of the funders, and we sought to accommodate their purposes as well.

If you are an evaluator by profession, our story of the loft in Cape Town will bring back memories of similar experiences-the first encounters with a new evaluation in the making. If you are a manager, such encounters with contractors will come to mind. The backdrop in either case is a set of questions about the evaluation. These are often simply tacit: they are hidden in the Request for Proposals or, at best, they are hinted at in the winning consultant's bid. The extent to which the client is ready for a collaborative, utilizationfocused evaluation that enhances organizational learning is often taken for granted. Collaborative Approaches to Evaluation (CAE) and UtilizationFocused Evaluation (UFE) belong to a family of evaluation frameworks that promotes the use of evaluation for decision making, with emphasis on engaging the people who will be the actual users of the evaluation findings (Christie \& Alkin, 2012; Cousins, Whitmore, \& Shulha, 2013; Cousins, Whitmore, Shulha, Al Hudbid, \& Gilbert, 2015). These approaches are conducive to organizational learning, as they invite evaluation purposes that address reflection on process, strategy, and overall project management. They contrast 
with conventional approaches where a funder or donor imposes evaluation uses that often emphasize accountability, and where the implementing partner is often marginal to the evaluation design and delegated to the role of data provider. There is a tension here between a top-down design with a focus on accountability and a learning-oriented one that values participatory learning. For an evaluator, recognizing which approach is possible becomes a strategic decision.

We have learned to address this issue head on: the level of readiness is a lynchpin that shapes every subsequent step of the process.

Upon reviewing Michael Quinn Patton's work (2008) on utilizationfocused evaluation (UFE), we came across the notion of considering project or organization readiness for this kind of evaluation, as well as evaluators' own readiness to play a different role. We have found that readiness is about the willingness to turn evaluations into useful exercises for the proponents, as opposed to simply bureaucratic accountability obligations. In Patton's UFE, the evaluators' performance is judged simply by the level of use of the findings, and of the process. The origins of the concepts of readiness lie not in evaluation books, but in project management science. Readiness means having a sense of what is doable within a specific organizational or project situation, of having the imagination to explore what needs to be learned, and of being willing to learn on the part of all levels of an organization (Brodhead \& Ramírez, 2014).

The notion of organizational readiness has been around for some time, often with emphasis on the extent to which an institution is able to gain evaluative capacity (Preskill and Torres, 1999). There are several tools available, including the Readiness for Organizational Learning and Evaluation (ROLE) instrument based on Preskill \& Torres, a checklist for institutionalizing evaluation (Stufflebeam, 2002), and a checklist for building organizational evaluation capacity (Volkov \& King, 2007). There is research to validate both the "evaluation checklist for organizational readiness for evaluation capacity development" (Walker-Egea, 2014) and the assessment of an organization's readiness for learning and evaluative inquiry (Preskill, Torres, \& Martinez-Papponi, 1999). In the case of ROLE, questions address six dimensions: culture, leadership, systems and structures, communication, teams, and evaluation.

Readiness has connotations of who decides on the purposes of an evaluation, what room there is to learn, and the extent to which the organizational culture embraces change. In our experience, the norm is for a funder to impose an evaluation design on a grantee. As a result, the process is perceived as a necessary evil, and there is little or no expectation of much good emerging from the process. With utilization-focused evaluation's focus on readiness, we feel there is an opportunity to shift away from the norm (see Table 1 for a comparison). 
Table 1. Contrasting Conventional vs. Utilization-Focused Evaluation

\begin{tabular}{|c|c|c|}
\hline & Conventional & Utilization focused \\
\hline $\begin{array}{l}\text { Readiness } \\
\text { assessment }\end{array}$ & Disregarded & $\begin{array}{l}\text { An integral step that includes } \\
\text { project readiness as well as } \\
\text { evaluator readiness }\end{array}$ \\
\hline $\begin{array}{l}\text { Control of } \\
\text { the evalua- } \\
\text { tion design }\end{array}$ & $\begin{array}{l}\text { Funder or donor } \\
\text { imposes the purpose } \\
\text { and the evaluation design }\end{array}$ & $\begin{array}{l}\text { Project managers invited to } \\
\text { participate in the evaluation } \\
\text { design }\end{array}$ \\
\hline $\begin{array}{l}\text { Evaluation } \\
\text { purpose of } \\
\text { use }\end{array}$ & $\begin{array}{l}\text { Evaluation mainly for } \\
\text { accountability, although } \\
\text { other uses can be added }\end{array}$ & $\begin{array}{l}\text { A variety of uses combined: evalu- } \\
\text { ation for learning and adapting, as } \\
\text { well as shared accountability; and } \\
\text { developmental }\end{array}$ \\
\hline $\begin{array}{l}\text { Role of stake- } \\
\text { holders }\end{array}$ & $\begin{array}{l}\text { Evaluation is led by an } \\
\text { external player-done to } \\
\text { the stakeholders }\end{array}$ & $\begin{array}{l}\text { Evaluation understood / under- } \\
\text { taken by the key stakeholders }\end{array}$ \\
\hline $\begin{array}{l}\text { Facilitation } \\
\text { of use }\end{array}$ & $\begin{array}{l}\text { Disregarded or taken for } \\
\text { granted }\end{array}$ & $\begin{array}{l}\text { An integral step to ensure actual } \\
\text { use }\end{array}$ \\
\hline $\begin{array}{l}\text { Meta evalua- } \\
\text { tion }\end{array}$ & Disregarded & $\begin{array}{l}\text { An important add-on (when } \\
\text { resources allow) that enhances } \\
\text { reflection and evaluative learning }\end{array}$ \\
\hline $\begin{array}{l}\text { Evaluation } \\
\text { literacy }\end{array}$ & $\begin{array}{l}\text { Limited gains, as often } \\
\text { evaluation is equated with } \\
\text { outside judgements }\end{array}$ & $\begin{array}{l}\text { Gains in evaluative thinking; a } \\
\text { sense of ownership over process } \\
\text { and findings }\end{array}$ \\
\hline
\end{tabular}

\section{THREE PROMPTS ABOUT READINESS}

We have gleaned some lessons from our work that we have summarized into three elements of readiness that serve as prompts:

1. the power to design,

2. the commitment to learn, and

3. the emphasis on building an evaluation culture.

\section{Prompt 1: The power to design}

In the non-profit world, and in international development assistance, the funding agency normally holds the prevailing power in the relationship with the grantee. The disbursing officers are accountable, and the grantee organization is bound by an agreement to deliver goods and services. An evaluation is imposed to confirm the achievement of the objectives; the design is based on an original logical framework, and its implementation is often contracted out. This is the context that many readers will recognize; it leads to "the norm" in our table. However, when the funder is willing to relinquish and/or share this power to design evaluation, a different dynamic begins to emerge, as we experienced in this evaluation practice. 
The board table was cluttered, with loads of coffee mugs, papers, computers and computer cords surrounding the three members of the project team (the executive director, one of the researchers, and the person who was called upon to run everything in the office-and then some) along with the members of the evaluation team and a potential user on Skype from Cairo. The steps in the process were not always clear, but they worked well enough to get us through the determination of a roster of "users" (including those in the room and the program officer from Cairo, who decided to take off his funder hat and consider himself a "user").

Today there is a growing demand for evaluation that engages those affected by the intervention: the target population, managers of the program, those who must make program and policy decisions, program designers, and others. As a result, not only do more people want evaluation involvement, but they also want to learn about and from it. This process has also resulted in discussions regarding the purposes of evaluation and a response to the question: who it is for? The very question of "who" indicates that evaluation does not necessarily have to be prepared for the donor or funder and thus does not only have to be about accountability.

In our example, the project managers invited the project officer (from the funding organization) to join the "user team." (In this UFE model, the five evaluators played the role of facilitators of evaluation design, where the "user team" had control over the purposes or "uses" of the evaluation. Once the evaluation design was set, the evaluators collected the evidence and produced the evaluation report.) The project officer agreed and expressed an interest in learning about what made the initiative work, to verify outcomes and to determine the conditions that enabled success. He stated that he would "take off his funder hat" and join the evaluation design team-the owners of the process. In our recent experience doing evaluations globally, we have come across very few funders who have the courage to minimize the power differences and invite their grantees to become evaluation partners, thus enabling a team to take the lead. In taking this step, the funders have witnessed how the evaluation reports get used both by the grantees and by the funding agency. They have watched the evaluation process turn into a joint learning endeavour. These commissioners of evaluation have created a learning space, which has been made possible thanks to the learning culture of their organizations.

Some years back we published a short book (Ramírez \& Brodhead, 2013) summarizing our experience with utilization-focused evaluation; it includes a section written by our funder (IDRC), entitled "What benefit does UFE bring to commissioners of evaluation?", and it elaborates on what it takes for donors to support innovative development initiatives, including challenging traditional views on evaluation.

\section{Prompt 2: The commitment to learn}

When a team of primary evaluation "users" is faced-for the first time-with the opportunity to shape an evaluation, they get that "deer in the headlights" expression. "You mean I can decide what this is for?" Having the space to decide on the 
purposes of an evaluation is both liberating and scary. It is about taking ownership over a process that has the historic connotation of external control and imposed parameters-an accountability focus. However, the antidote is the second readiness element: a willingness to learn.

Next, we continued with a definition of the main uses, and made a start at identifying the key evaluation questions. The process was not easy (i.e., how to capture ten years of work in 17 countries), and on later reflection this was really the pivotal point of the evaluation. If you get these steps right, the rest usually fall into place. We weren't able to complete the process while we were with the team in Cape Town. We went back to our respective countries and used Skype and telephone (when Skype didn't work for our colleague in Zimbabwe). Fortunately, we could lean on the team members versed in UFE to get us through the final round of determining key evaluation questions. Once we had these questions in place, it was time to identify the evidence needed, where that evidence could be found, and which data-collection instruments could most effectively be used to obtain the information.

The evaluation team finally settled on six evaluation uses or purposes:

1) to validate the outcomes for the funder;

2) to provide evidence of, and document outcomes and relevance for, other funders;

3) to inform an internal process of transition (leadership, skills, funding);

4) to chart outcome pathways;

5) to chart communication strategy outcomes; and

6) to inform organizational sustainability.

Managers will recognize the focus on survival, yet they will see that other purposes call for learning to facilitate strategic adaptation. The evaluation was intended to improve organizational structure, review strategy, and revise communication plans. The evaluation purposes included accountability to funders, which was combined with other reporting/learning priorities.

\section{Prompt 3: The emphasis on building an evaluation culture}

At the heart of this evaluation work is learning-by-doing-or experiential learning. When the evaluation users are engaged in deciding what to evaluate, what questions to ask, what evidence to seek, and what tools to use to collect and analyze findings, they learn about evaluation. Crucially, they also take ownership of the results (Levine \& Griñó, 2015). While we have referred to this process as "participatory suffering," it has no replacement. We have shied away from standalone evaluation training workshops for this very reason: people learn when they are able to get timely advice, at the moment when decisions have to be made during implementation. An important feature of UFE is facilitating the use of the findings, and of the process. This emphasis means that utilization is built into the evaluation contract. In our work, we have gone beyond producing an evaluation report (Ramírez, Quarry, Dhewa, Nyangaga, \& Brodhead, 2014) and also 
prepared a case study (Yin, 1984) that summarizes the evaluation process itself (DECI-2 Project, 2014). It is a form of meta-evaluation-the last step in UFE.

In February 2014, an opportunity came up for the evaluation team to reassemble in Cape Town. The draft report had been sent ahead, along with tentative recommendations so that the users and the evaluation team could review the findings, correct any misinformation, and collectively decide on recommendations. It was a hectic time trying to cram all this work into a two-day period while the executive director was concurrently distracted by imminent changes within the organization, its staff, its structure, and indeed its future direction.

The team once more sat together in the room with the crow's-nest view and worked its way through the draft report-sometimes forming little sub-groups to rewrite parts of the text. The intake of information was fast and furious, and it was a struggle to keep up and "get it all done" within the allotted time. Several iterations of the Theory of Change were worked on. In the end, the evaluation team did draft the key recommendations, but each one had been thoroughly discussed with the evaluation users before committing them to text. A final write up and a Skype call with the executive director ended the process in time to allow the organization to use the evaluation for fundraising for their future initiatives. Most notably, the Theory of Change produced became the centrepiece for a promotional book.

\section{COLLABORATION LEAVES AN IMPRINT}

Managers will be familiar with double-loop learning, a centrepiece for reflective practitioners. Learning involves the detection of error and the correction of further action (Argyris and Schön, 1978; Schön, 1983). When something goes wrong, it is common to look for another strategy that will address the issue and its context, without challenging goals or assumptions. For Argyris and Schön (1996), this constitutes single-loop learning. In contrast, double-loop learning brings in a questioning of assumptions and the factors at play. This can lead to changes in strategy, in framing, and in goals. The analogy is that single-loop learning is like a thermostat, where a person adjusts the setting to control temperature, while in double-loop learning, the location of the thermostat may be altered, the heating system replaced, or insulated windows installed (Smith, 2013).

In UFE, facilitating the use of the findings is a dedicated activity. It allows the evaluation users to review the findings, the analysis, and the conclusions and recommendations. This step also includes a reflection on the process. Facilitating a reflection on the process is about redefining the meaning of evaluation. In addition, producing meta-evaluations has proven to be a means to enhance organizational learning. We have found that our clients and partners gain evaluative thinking and capacity through this process. Our Cape Town partners reviewed the Evaluation Report, especially the theory of change that depicted the actual mechanisms by which they had achieved high-level outcomes. They recognized their work in the diagram; they in turn profiled it in a subsequent publication confirming the contribution of their research (RIA, 2016). 
Once this collaborative approach has been experienced, it leaves an imprint, a way of thinking. We jokingly say that it appears to be an irreversible infection. However, this experience is possible only when the host organization exhibits a learning culture or is seeking to encourage one and wishes to build internal capacity (Bourgeois \& Cousins, 2015; Mayne, 2009). In turn, this potential is often enhanced when the power differential with their funding partners is minimized.

While evaluation professionals may not be able to resolve the tension between collaborative, learning-oriented evaluation and conventional, top-down approaches, they do have options. On the one hand, those working within agencies that have evaluation units can seek to create readiness conditions: recall the six dimensions of readiness by Preskill et al. (1999), where gradual change could be introduced: culture, leadership, systems and structures, communication, teams, and evaluation. Where there is a commitment by senior management to enhance evaluation literacy, there should be room to create more learning and reflection opportunities. On the other hand, for independent evaluators, the notion of readiness becomes a Litmus test for the type of evaluation that a client is willing to embrace. These three elements of readiness that we outline are interconnected, and we refer to them as prompts to emphasize their practical application. Elsewhere, we have referred to readiness as the undiscovered value-added element of UFE (Brodhead \& Ramírez, 2014). Professional evaluators my find some room to facilitate readiness, where some of the major elements are conducive. They may be able to assist a client in broadening the purposes of an evaluation to reduce the tension between accountability and learning.

\section{ACKNOWLEDGEMENTS}

The experience described in this article is one of several evaluations completed by the DECI-2 project that was funded by IDRC (Canada) and UKAid. The project continues as DECI-3 and the website includes case studies and several resource materials: http://evaluationandcommunicationinpractice.net

\section{REFERENCES}

Argyris, C., \& Schön, D. (1978). Organizational learning: A theory of action perspective. Reading, MA: Addison Wesley.

Argyris, C., \& Schön, D. (1996). Organizational learning II: Theory, method and practice. Reading, MA: Addison Wesley.

Brodhead, D., \& Ramírez, R. (2014, March). Readiness and mentoring: Two touchstones for capacity development in evaluation. Paper presented at the CDI Conference: Improving the use of $M \& E$ processes and findings, Wageningen, The Netherlands.

Bourgeois, I. \& Cousins, J.B. (2015). Reaching organizational goals through improved evaluation capacity. Canadian Government Executive 21(1). Retrieved from http:// canadiangovernmentexecutive.ca/reaching-organizational-goals-through-improvedevaluation-capacity/ 
Christie, C.A., \& Alkin, M.C. (2012). An evaluation theory tree. In M.C. Alkin (Ed.), Evaluation roots: $A$ wider perspective of theorists' views and influences (2nd ed., pp. 11-57). Thousand Oaks, CA: Sage.

Cousins, J.B., Whitmore, E., \& Shulha, L. (2013). Arguments for a common set of principles for collaborative inquiry in evaluation. American Journal of Evaluation, 34(1), 7-22. https://doi.org/10.1177/1098214012464037

Cousins, J.B., Whitmore, E., Shulha, L., Al Hudbid, H., \& Gilbert, N. (2015). Principles to guide collaborative approaches to evaluation. University of Ottawa: Centre for Research on Educational and Community Services.

DECI-2 Project. (2014). The evaluation of Research ICT-Africa (RIA): A case study. Ottawa: New Economy Development Group. Retrieved from http://evaluationandcommunication inpractice.net/knowledgebase/the-evaluation-of-research-ict-africa-ria-a-case-study

Levine, C., \& Griñó, L. (2015). Local ownership in evaluation: Moving from participant inclusions to ownership in evaluation decision-making. Washington, DC: The Rockefeller Foundation \& InterAction.

Mayne, J. (2009). Building an evaluation culture: The key to effective evaluation and results management. Canadian Journal of Program Evaluation, 24(2), 1-30.

Patton, M.Q. (2008). Utilization-focused evaluation (4th ed.). Thousand Oaks, CA: Sage.

Preskill, H., \& Torres, R.T. (1999). Evaluative inquiry for learning in organizations. Thousand Oaks, CA: Sage.

Preskill, H., Torres, R.T., \& Martinez-Papponi, B. (1999, November). Assessing an organization's readiness for learning from evaluative inquiry. Paper presented at the American Evaluation Association annual conference. Orlando, FL.

Ramírez, R., \& Brodhead, D. (2013). Utilization focused evaluation: A primer for evaluators. Penang, Malaysia: Southbound.

Ramírez, R., Quarry, W., Dhewa, C., Nyangaga, J., \& Brodhead, D. (2014). Research ICT Africa-DECI-2 Collaboration: Evaluation Report. Prepared by DECI-2 for Research ICT Africa (Cape Town) and IDRC (Cairo). Retrieved from https://evaluationand communicationinpractice.net/knowledgebase/research-ict-africa-deci-2-collaborationevaluation-report/

RIA. (2016). How ordinary people got connected despite the connected people. Cape Town, South Africa: Research ICT Africa \& IDRC.

Schön, D.A. (1983). The reflective practitioner: How professionals think in action. London, England: Temple Smith.

Smith, M.K. (2013). Chris Argyris: Theories of action, double-loop learning and organizational learning. the encyclopedia of informal education. Retrieved from http://infed.org/mobi/ chris-argyris-theories-of-action-double-loop-learning-and-organizational-learning/

Stufflebeam, D.L. (2002). Institutionalizing evaluation checklist. Evaluation Checklists Project. Retrieved from https://www.wmich.edu/sites/default/files/attachments/ u350/2014/institutionalizingeval.pdf

Volkov, B.B. \& King, J.A. (2007) A checklist for building organizational evaluation capacity. Retrieved from https://www.wmich.edu/sites/default/files/attachments/u350/2014/ organiziationevalcapacity.pdf 
Walker-Egea, C.F. (2014). Design and validation of an evaluation checklist for organizational readiness for evaluation capacity development (Doctoral dissertation). Retrieved from scholarcommons.usf.edu/etd/5399

Yin, R.K. (1984). Case study research: Design and methods. Beverly Hills, CA: Sage.

\section{AUTHOR INFORMATION}

Ricardo Ramírez is an independent researcher and consultant based in Guelph, Ontario. His consulting and research work includes communication planning, participatory evaluation, and capacity development. He is a credentialed evaluator (Canadian Evaluation Society). His doctoral work focused on how rural and remote communities harness information and communication technology. He is co-principal investigator of the DECI-2 project.

Dal Brodhead is the director of the New Economy Development Group, a value-based consulting firm based in Ottawa. Dal brings a strong background in community development, project management, and applied research in Canada and internationally. $\mathrm{He}$ led one of CIDA's largest micro-finance and human development projects in Bangladesh (1991-2002). Dal is co-principal investigator of the DECI-2 project.

Wendy Quarry is an Ottawa-based communication specialist with over three decades of experience in both communication and evaluation. She has worked with governments, the private sector, NGOs and research institutes and has lived with her family in Colombia, Ghana, Pakistan, India, and Afghanistan. She collaborates with Dal Brodhead and Ricardo Ramírez in the DECI-2 project. 